\title{
Study on the Mental and Emotional Cost of Incarceration
}

-Prison-Related PTSD

\author{
Cornelius D. Jones \\ Department of Trauma Research, Jones Counseling Services, Jacksonville, FL, USA \\ Email: drcdjones@gmail.com
}

How to cite this paper: Jones, C.D. (2020) Study on the Mental and Emotional Cost of Incarceration. Open Journal of Medical Psychology, 9, 41-49.

https://doi.org/10.4236/ojmp.2020.92004

Received: February 3, 2020

Accepted: March 22, 2020

Published: March 25, 2020

Copyright $\odot 2020$ by author(s) and Scientific Research Publishing Inc. This work is licensed under the Creative Commons Attribution International License (CC BY 4.0).

http://creativecommons.org/licenses/by/4.0/

(c) (i) Open Access

\begin{abstract}
Post-traumatic stress disorder (PTSD) is a psychiatric disorder that is the result of personal experiences directly involved with or witnessing traumatic or life-threating events. PTSD has profound psychobiological correlates, which can impair the person's daily life and be life-threatening. The disorder is typically associated with military combat, acts of terrorism, sexual assault, bullying, exposure to abusive and toxic environments. The culture of prison encompasses and is the direct catalyst for consistent exposure to each of these elements. Considering that the United States leads the free world in the rate of incarceration, Prison-related PTSD is a serious public health and social issue. A sharp rise in ex-offenders that meet 3 or more of the criteria for diagnosing post-traumatic stress disorder (PTSD) from the Fifth Edition of the Diagnostic and Statistical Manual of Mental Disorders is alarming. We review the numbers and introduce a new perspective on how the Department of Corrections and Department of Justice can play a vital role by working to correct this problem. We discuss the need to provide long-term care for this underserved population, particularly those convicted of non-violent crimes. We present arguments in support of the notion there should be professional clinical resources available for individuals released from prison to help manage the symptoms of PTSD that were created primarily through incarceration.
\end{abstract}

\section{Keywords}

Prison-Related Post-Traumatic Stress Syndrome, Allostasis, Evidence-Based Research, Mental and Emotional Cost of Incarceration

\section{Introduction}

There is no secret that the ex-felon population is underserved as the result of the 
nation's tough on crime approach. Such programs as reentry, apprenticeship, work release, halfway homes, etc. are designed to help individuals adapt to life outside of prison. Although, these opportunities for reclamation exist what they experienced while in custody is often overlooked but are contributing factors to many ex-offenders inability to readjust to society. In the United States, there are a variety of government agencies involved in the criminal justice system to collect critical data on the price of imprisonment. Unfortunately, that data is not designed to help policymakers, or the public understand exactly how the longterm exposure to trauma while in custody effect those that were previously incarcerated.

At least $95 \%$ of people in all state prisons will be released at some point; nearly $80 \%$ of them will be released to parole supervision [1]. The mental and emotional cost of incarceration is a risk to public safety. The numbers reported are often deflated to minimize the severity of how many people are locked up across the country. Individuals in state, federal, and private prisons are more prevalent to experience trauma than those that serve in military combat zones. According to a Prevalence Estimates of Combat-Related PTSD: A Critical Review study, 2\% $17 \%$ of combat veterans are diagnosed with PTSD [2]. To paint a clearer picture, a total of 7,470,000 service members have served in World War II, Vietnam, Iraq, and Afghanistan [3]. Each year more than 600,000 people enter prison to start their sentences. Another 650,000 people are released from prison per year [4]. Over the past 20 years since America has been at war, 5,530,000 more people were released from prison than the total number of people that served in American wars over an 81-year span.

These numbers do not include people that go to jail 10.6 million times per year. Some are only arrested and make bail within hours or days, while many others are too poor to make bail and remain behind bars until their trial. Only a small number (less than 150,000 on any given day) have been convicted and are generally serving misdemeanors sentences under a year. These numbers are excluded from the 2.3 million people that the Bureau of Prisons include in their statistics. It is important to note there are more than 5 million people behind bars in America at any given time. As of January 2020, which is the time that this study was concluded we have 1719 state prisons, 109 federal prisons, 1772 juvenile correctional facilities, 3163 local jails, and 80 Indian Country jails as well as military prisons, immigration detention facilities, civil commitment centers, state psychiatric hospitals, and prisons in the U.S. territories. Traumarelated phobias that maintain dissociations are common among people that struggle with trauma. The problem is when an individual is stuck in trauma, each dissociative part is relatively isolated from other parts by these phobias, which are maintained by painful conflicts and memories that cannot be realized, and by avoidance strategies [5]. They experience intense conflicts between trauma-related perceptions and impulses [6].

\subsection{Prisons and Numbers of Incarcerated}

The state of Florida where this research was originated has one of the highest 
incarceration rates in the nation and pays less than most other states to house offenders. In a 2018 study, the state of Florida had a total of 176,000 people behind bars. The state prison system had 99,000 and the federal prison had 19,000 in custody. The other remaining individuals accounted for 53,000 in local jails, 2900 in youth facilities and 2100 that were in involuntary confinement. While the state's incarceration rate decreased since 2014, the state remains well above the national average. Florida has a high percentage of residents who are incarcerated. In fact, Florida's incarceration rate of 833 people per 100,000 residents is higher than the national average of 660, according to the Bureau of Justice Statics [7]. The Florida Department of Corrections (FDC) is the third largest state prison system in the country with a budget of $\$ 2.7$ billion, approximately 95,000 inmates incarcerated and nearly 164,000 offenders on active community supervision (probation) as of January 2020. The Department has 145 facilities statewide, including 50 correctional institutions, seven private partner facilities, 17 annexes, 34 work camps, three re-entry centers, 12 FDC operated work release centers, 18 private work release centers, two road prisons, one forestry camp and one basic training camp. FDC is the largest state agency in Florida. Over $80 \%$ of its staff are either certified correctional officers or probation officers [8]. In a 2015 study conducted by Vera on the Price of Prisons, the state of Florida only spent and average of $\$ 19,069$ per inmate [9].

Throughout the nation, it is reported that rates of exposure to violence or traumatic events among male prison population are between $62 \%$ to $100 \%$ which doubles all other male community-based populations. The major two contributors are physical abuse and sexual abuse. On average $60 \%$ of men that are in prison have symptoms and signs of severe to moderate PTSD. This means that $30 \%-60 \%$ of those who are exposed to physical trauma including assault, and $43 \%-75 \%$ of men who were victims of sexual violence in prison [10]. Please note that these numbers exclude those who failed to report incidents out of shame or fear. It is also noteworthy to include that the highest rates of PTSD occur in male inmates who have other mental health conditions.

According to the January 2020 statistics published by the Federal Bureau of Prisons, $45.3 \%$ of federal inmates are in custody for drug offenses. Another $19.3 \%$ are in for Weapons, Explosives, Arson; 3.5\% are in for Robbery; $10.3 \%$ are in for Sexual Offenses; and 3.2\% are in for Homicide, Aggravated Assault, and Kidnapping Offenses. The remaining offenses are for Burglary, Larceny, Property Offenses, Continuing Criminal Enterprises, Extortion, Fraud, Bribery, Immigration, Miscellaneous and Courts of Corrections. Of the 162,268 prisoners in federal custody, less than 20,000 are considered violent offenders. It is important to note that these numbers don't represent those that are housed in State Prisons [11].

The emotional horrors associated with what they witness, and experienced will leave prison with them once they come out. Although most males won't admit it, they are subjected to physical, sexual, and mental trauma on a regular basis during their time of incarceration. Their trauma can come at the hands of 
fellow inmates or by the staff that is paid to protect them. Trauma doesn't normally present itself when the individual is still in the environment that the event occurs. The state of numbness affords them the opportunity to become detached from the traumatic ordeal. It isn't until the individual is removed from the environment that the brain fully processes what has occurred.

Considering that $73 \%$ of male and $55 \%$ of female inmates serving in State Prisons have at least 1 mental health problem [12]. When new trauma is introduced to someone with a mental illness it can intensify their condition. The limited resources available to them does little good to help them to get reintegrated into society, if they are still living behind the wall mentally. Most people coming out of prison already have temporary difficulty adjusting and coping, to the outside world. When trauma is involved and unresolved, it only complicates the process, but with time and good self-care, they can get better.

\subsection{PTSD-Overview}

DSM-5 has made several important changes to the criteria of post-traumatic stress disorder, the most significant being a more specific definition of the type and nature of the exposure to a threat. Under DSM-5, post-traumatic stress disorder (PTSD) is an anxiety disorder that develops in relation to an event which creates psychological trauma in response to actual or threatened death, serious injury, or sexual violation. The exposure must involve directly experiencing the event, witnessing the event in person, learning of an actual or threatened death of a close family member or friend, or repeated first-hand, extreme exposure to the details of the event. Traumas experienced may involve war, natural disasters, car accidents, sexual abuse and/or domestic violence. A formal diagnosis of PTSD is made when the symptoms cause clinically significant distress or impairment in social and/or occupational dysfunction for a period of at least one month. The symptoms cannot be due to a medical condition, medication, or drugs or alcohol.

\section{Method}

\subsection{Participants and Process}

Subjects for this research consisted of 1000 individuals that were all convicted and sentenced to serve time in a state, federal, private, county, or juvenile correction facility within the United States. The sample size of 1000 subjects were selected to provide more accurate results. None of the subjects were paid to participate in this volunteer study. The study was conducted over a 7-month period and averaged 143 responses per month. The subjects of this research represented 42 states in the nation. All states within the United Sates were included, only 9 states didn't have any participants.

\subsection{Procedures}

To protect the subject's identity, no names, races or personal information was 
asked or included in this study. Only 121 out of 1000 subjects filled out questionnaires by hand, the remaining 879 completed the questionnaires online. The 121 subjects were all approached in person coming out of the Florida State Parole and Probation office in Jacksonville, FL and asked to take part of the study. To avoid any conflict of interest for subjects still under state supervision, an online questionnaire was created.

The Prison-Related PTSD Questionnaires were created and distributed through Social Justice Reform, Prison Reform and advocacy groups throughout social media platforms. The largest and most active Criminal Justice Reform, Prison Reform, and advocacy groups on social media were targeted to reach more people. Each subject utilized a link that was generated to submit their responses online. The information provided was automatically entered into the database and created the final statistics. Subjects were only allowed to use the link once to prevent duplicate submissions so we could gather accurate data. The link was shareable to other participants, but password protections and IP Restrictions were active. No partial submissions were collected, only the information from completed questionnaires were saved in the system. There were 67 questionnaires excluded from being used in the data due to incomplete or unanswered questions. A total of 25 questions were included on the questionnaire, 14 of them were designed to be trauma specific to identify present symptoms of trauma. The questions were designed to show how many of the subjects that participated present symptoms of trauma without providing them with an actual clinical diagnosis. Out of the 1000 subjects that took part of this study, 721 believe they may suffer from PTSD due to incarceration.

\section{Symptoms required for diagnosis of PTSD}

All the criteria are required for the diagnosis of PTSD. Only one symptom is required for criteria A-C, however two are required for criteria $\mathrm{D}$. The following text in the chart summarizes the diagnostic criteria.

\subsection{Demographics}

Participants also provided their age, gender, state of conviction and years served.

\section{Results}

\subsection{Characteristics of the Odds Ratio Sample}

Demographic characteristics, criteria and internalizing symptoms are described in Table 1.

Disturbing memories or thoughts after prison $(\mathrm{OR}=0.61 ; 95 \%$ CI $[0.57$; $0.65])$.

Irritability or outburst of anger ( $\mathrm{OR}=0.45 ; 95 \% \mathrm{CI}[0.41 ; 0.49])$.

Disturbing memories or thoughts from prison very often $(\mathrm{OR}=0.45 ; 95 \% \mathrm{CI}$ $[0.41 ; 0.49])$.

Experience persistent negative emotions ( $\mathrm{OR}=0.52 ; 95 \% \mathrm{CI}[0.48 ; 0.56])$.

Irritability or outbursts of anger ( $\mathrm{OR}=0.45 ; 95 \% \mathrm{CI}[0.41 ; 0.49])$. 
Table 1. Characteristics of prison related PTSD sample $(N=1000)$.

\begin{tabular}{|c|c|}
\hline Criterion A: Traumatic Event & Criterion B: Intrusion or Re-Experiencing \\
\hline $\begin{array}{l}\text { Trauma survivors must have been exposed to } \\
\text { actual or threatened: } \\
\text { - Direct exposure } \\
\text { - Witnessing the trauma } \\
\text { - Learning that a relative or close friend was } \\
\text { exposed to trauma } \\
\text { - Indirect exposure to aversive details of the } \\
\text { trauma, usually in the course of professional } \\
\text { duties (e.g., first responders, medics) }\end{array}$ & $\begin{array}{l}\text { These symptoms envelope ways that someone } \\
\text { re-experiences the event. This could look like: } \\
\text { - Unwanted upsetting memories } \\
\text { - Nightmares } \\
\text { - Emotional distress after the exposure to } \\
\text { traumatic reminders } \\
\text { - Physical reactivity after exposure to traumatic } \\
\text { reminders } \\
\text { - Psychological and physical reactivity to } \\
\text { reminders of the traumatic event, such as an } \\
\text { anniversary }\end{array}$ \\
\hline $\begin{array}{l}\text { The exposure can be: } \\
\text { - direct } \\
\text { - witnessed } \\
\text { - indirect, by hearing of a relative or close } \\
\text { friend who has experienced the } \\
\text { event-indirectly experienced death must be } \\
\text { accidental or violent } \\
\text { - repeated or extreme indirect exposure to } \\
\text { qualifying events, usually by } \\
\text { professionals-non-professional exposure } \\
\text { by media does not count }\end{array}$ & \\
\hline
\end{tabular}

\section{Criterion C: Avoidant Symptoms}

Criterion D: Negative Alterations in Mood or Cognitions
Avoidant symptoms describe ways that someone may try to avoid any memory of the event, and must include one of the following:

- Avoiding thoughts or feelings

- Avoiding people or situations connected to the traumatic event
This criterion is new but captures many symptoms that have long been observed by PTSD sufferers and clinicians. Basically, there is a decline in someone's mood or thought patterns, which can include:

- Memory problems that are exclusive to the event

- Negative thoughts or beliefs about one's self or the world

- Distorted sense of blame for one's self or others, related to the event

- Negative Affect

- Decreased interest in activities

- Feeling isolated or disconnected from other people

- Difficulty experiencing positive affect

\section{Criterion E: Increased Arousal Symptoms}

Criteria F, G and $\mathrm{H}$

Increased arousal symptoms are used to describe the ways that the brain remains "on edge," wary and watchful of further threats. Symptoms include the following:

- Irritability or aggression

- Risky or destructive behaviors

- Difficulty falling or staying asleep

- Heightened startle reaction

- Hypervigilance

- Difficulty concentration
These criteria all describe the severity of the symptoms listed above. Symptoms create distress or functional impairment (e.g., social, occupational). Basically, they have to have lasted at least a month, seriously affect one's ability to function and can't be due to substance use, medical illness or anything except the event itself. 
Disturbed sleep because of bad dreams or nightmares about things I witnessed in prison $(\mathrm{OR}=0.65 ; 95 \% \mathrm{CI}[0.64 ; 0.68])$.

Feelings of guilt or shame for your prison experience $(\mathrm{OR}=0.49 ; 95 \% \mathrm{CI}$ $[0.45 ; 0.53])$.

Flashbacks (OR $=0.54 ; 95 \% \mathrm{CI}[0.50 ; 0.58])$.

Find it difficult to distract myself from intrusive thoughts $(\mathrm{OR}=0.56 ; 95 \% \mathrm{CI}$ $[0.52 ; 0.60])$.

Witnessed a traumatic event in prison ( $\mathrm{OR}=0.87 ; 95 \% \mathrm{CI}[0.85 ; 0.89])$.

No history of post-traumatic stress prior to prison $(\mathrm{OR}=0.88$; $95 \% \mathrm{CI}[0.86$; 0.90]).

Struggle with prison related trauma $(\mathrm{OR}=0.47 ; 95 \% \mathrm{CI}[0.43 ; 0.51])$.

\subsection{Association between Prison and Symptoms of Trauma}

Of the 1000 subjects in the study $79.9 \%$ met criteria for irritability or anger, $87.7 \%$ met criteria for hypervigilance, $93.7 \%$ reported and met criteria for nightmares and sleep disturbance. $83.2 \%$ met criteria for feelings of guilt and shame. $91.7 \%$ met criteria for intrusive symptoms, $86.7 \%$ met criteria for direct exposure or witnessed a traumatic event in prison. The question on being a victim of sexual assault while in prison resulted in $29.9 \%$ which was 299 out of 1000 participants saying yes. Another $88.7 \%$ met criteria for flashbacks and emotional distress. Only $10.7 \%$ of all the subjects that took part in this study reported having a previous history of post-traumatic stress disorder prior to going to prison. More than $83.89 \%$ reported not being offered any mental health or general counseling for what they experienced while in prison. Only $9.58 \%$ of those that completed the questionnaire reported that they sought professional help on their own. However, $72.1 \%$ reported that they believe that they struggle with Prison Related PTSD. The remaining percentages of $11.74 \%$ reported no, $8.69 \%$ reported maybe, and $7.47 \%$ reported they were not sure. Prison-related PTSD is more prevalent than those that severed in military combat zones.

The number of Veterans with PTSD varies by service era:

- Operations Iraqi Freedom (OIF) and Enduring Freedom (OEF): About 11 20 out of every 100 Veterans (or between 11\% - 20\%) who served in OIF or OEF have PTSD in a given year.

- Gulf War (Desert Storm): About 12 out of every 100 Gulf War Veterans (or $12 \%)$ have PTSD in a given year.

- Vietnam War: About 15 out of every 100 Vietnam Veterans (or 15\%) were currently diagnosed with PTSD at the time of the most recent study in the late 1980s, the National Vietnam Veterans Readjustment Study (NVVRS). It is estimated that about 30 out of every 100 (or 30\%) of Vietnam Veterans have had PTSD in their lifetime [13].

These numbers only represent the number of veterans that have been officially diagnosed for combat PTSD and are not indicative of the broader scope of PTSD among all veterans. 


\section{Conclusions}

The study suggests that the rate of PTSD among ex-offenders is significantly higher than that in the general population, as reported elsewhere. It provides evidence that this dynamic is far more important than previously believed. Personal ethics are less predictive of such behavior as the result to the culture of violence that individuals are exposed to. Overall the findings suggest a strong need for PTSD treatment services for individuals formerly incarcerated in prisons.

The point prevalence of combat-related PTSD in studies of US military veterans ranges from about $2 \%-17 \%$, and the range tends to have a lower ceiling and is narrower among veterans than in the ex-offender population. Regardless of the "true" prevalence of prison-related PTSD, the disorder is associated with severe functional impairment (both occupational and social), high co-morbidity with other psychiatric disorders, high medical comorbidity, and/or reduced quality of life for the ex-offenders who suffer from it. Thus, it represents a significant costly and untreated illness to ex-offenders, their families, and society. Each state's Department of Corrections and the Federal Bureau of Prisons can help towards treatment through the appropriations of funds from their annual budgets to be distributed to local counseling agencies for services. The establishments of community partnerships between DOC, BOP, and local agencies will be key to provide long-term care to ex-offenders. Both support and time are necessary to recover from the traumatic event and regain emotional and mental stability after incarceration.

\section{Acknowledgments}

The author would like to acknowledge Carol Leonard of the Prison Reform Movement and social media communities that supported this effort by sharing the questionnaire link to the masses. All the individuals who agreed to participate in the research and used their personal experiences to assist in creditable feedback. Thanks to Kevi Jones, MBA, CSSBB the data analyst that was responsible for compiling the advanced statistics for this work. Gratitude is expressed to Seely L. Moore, BA., and Sameka Wilburn, BA, MSW for their contributions by providing insight and support for this research. A special thanks to Nubian Roberts a Criminal Justice Program Organizer of the New Florida Majority of Jacksonville, FL and the entire organizations' leadership. The author also recognizes Steven A. Brock, M.Div., and Sindy Jones, MPA of the 100 Strong Foundation, Incorporated for their organization continuous support.

\section{Conflicts of Interest}

The authors declare no conflicts of interest regarding the publication of this paper.

\section{References}

[1] Hughes, T. and James-Wilson, D. (2017) Bureau of Justice Statistics Reentry Trends in U.S.: Highlights. http://www.nicic.gov/bureau-justice-statistics-bjs-reentry 
[2] Richardson, L.K., Frueh, C.B. and Acierno, R. (2010) Prevalence Estimate of Combat Related PTSD: A Critical Review. Australian \& New Zealand Journal of Psychiatry, 44, 4-19. https://doi.org/10.3109/00048670903393597

[3] Chivers, C.J., Simon and Schuster (2018) Two Million Americans Have Served in Iraq and Afghanistan. 358. http://www.economist.com/books-and-arts/201808/

[4] Sawyer, W. and Wagner, P. (2010) Mass Incarceration: The Whole Pie. http://www.prisonpolicy.org/reports/pie2019.html

[5] Steele, K., Boon, S. and Hart, O. (2016) Testing Trauma-Related Dissociations: A practical Integrative Approach (Norton Series on interpersonal Neurobiology). W.W. and Norton, New York, 448-452.

[6] Fisher, J. (2017) Healing the Fragmentated Selves of Trauma Survivors Assessment. Routhledges, London, 232-238. https://doi.org/10.4324/9781315886169

[7] 2019-2020 Budget Overview-Florida Department of Corrections. http://www.dc.state.fl.us

[8] The Price of Prisons-Prison Spending in 2015: Vera (2015) http://www.vera.org/publications/price-of-prisons-2015-state-spending-trends-2015

[9] Thomas, L. (2017) Prison Post Traumatic Stress-New-Medical.net. https://news.medical.net/health/Prisoner-Post-Traumatic-Stress.aspx

[10] BOP: Statistics-Federal Bureau of Prisons (2020) http://www.bop.gov/about/statistics

[11] By the Numbers: Mental Health Behind Bars (2014) http://www.pbs.org/newshour/health/numbers-mental-illnes-behind-bars

[12] American Psychiatric Association (2013) Diagnostic and Statistical Manual of Mental Disorders. 5th Edition, American Psychiatric Press, Washington DC. https://doi.org/10.1176/appi.books.9780890425596

[13] How Common Is PTSD in Veterans?-PTSD: National Center for PTSD. http://www.ptsd.va.gov/understand/common/common_veterans.asp 